\title{
Construction Enterprise Resource Planning Implementation: Critical Success Factors - Lesson Learning in Taiwan
}

\author{
Yu-Cheng LIN ${ }^{a}$, Meng-Hsueh LEE ${ }^{b}$ and H. Ping TSERNG ${ }^{c}$ \\ a Ph.D. Candidate, Department of Civil Engineering, National Taiwan Univ., Taipei, Taiwan. \\ yucheng@ce.ntu.edu.tw \\ b Ph.D. Student, Department of Civil Engineering, National Taiwan Univ., Taipei, Taiwan. \\ r90521702@ntu.edu.tw \\ b Associate Professor, Department of Civil Engineering, National Taiwan Univ., Taipei, Taiwan. \\ hptserng@ce.ntu.edu.tw
}

\begin{abstract}
Enterprise Resource Planning (ERP) is the latest high-end solution information technology has lent to business application. Enterprise resource planning systems are highly complex information systems. The implementation of these systems is a difficult and high cost proposition that places tremendous demands on corporate time and resources. Many ERP implementations have been classified as failures because they did not achieve predetermined corporate goals. The paper identifies main success factors critical to a successful implementation. A summary of successful ERP implementation is presented based on lesson learned from the interviews with experts and discussed in terms of these key factors.
\end{abstract}

KEYWORDS: Enterprise resource planning; Construction Industry; Critical success factors

\section{INTRODUCTION}

The construction business environment is dramatically changing. Construction enterprises today face the challenge of increasing competition, expanding markets, and rising customer expectations. This increases the pressure on companies to lower total costs in the entire supply chain, shorten throughput times, drastically reduce inventories, expand product choice, provide more reliable delivery dates and better customer service, improve quality, and efficiently coordinate global demand, supply, and production. As the business world moves ever closer to a completely collaborative model and competitors upgrade their capabilities, to remain competitive, organizations must improve their own business practices and procedures. Companies must also increasingly share with their suppliers, distributors, and customers the critical in-house information they once aggressively protected. And functions within the company must upgrade their capability to generate and communicate timely and accurate information. To accomplish these objectives, companies are increasingly turning to enterprise resource planning (ERP) systems. ERP provides two major advantages that do not exist in non-integrated departmental systems: (1) a unified enterprise view of the business that encompasses all functions and departments; and (2) an enterprise database where all business transactions are entered, recorded, processed, monitored, and reported. This unified view increases the requirement for, and the extent of, interdepartmental cooperation and coordination. But it enables companies to achieve their objectives of increased communication and responsiveness to all stakeholders. Limited study has been conducted in the ERP implementation of construction industry, with most research consisting of case studies in other industries. Furthermore, critical success factors for enterprise resource planning implementation will be different than others because the characteristic of construction industry is different than others industries. Therefore, the paper present main factors critical to a successful implementation for construction industries based on the interview and literature review.

\section{PROBLEM STATEMENTS}

ERP systems implementation is a long-term program, not a short-term project that is finished just after system installation. Also, the price of ERP system is very expensive. Once organizations have purchased ERP packages from external vendors, a project team including external consultants and internal employees will be setup. However, the construction business is operated around projects. Each project is an end production to be delivered 
and is expected to be completed on time and within budget. Therefore, the implementation of core methodology for ERP is different since the production line is totally different. Furthermore, about 90 percent of ERP implementations are late or over budget and ERP implementation success rate is only about $33 \%$. The steep difference of ERP systems implementation success rates between construction industry and other industries produces a need of research to examine general and specificto-construction critical success factors.

\section{RESEARCH METHODOLOGY FRAMEWORK}

AND

This paper discusses what successful factors specialty to enterprise resource planning system implementation to construction enterprise. In current practice in Taiwan, many construction enterprises start to consider the implementation of ERP system for their enterprise. There are two construction companies that implement their ERP system successfully selected as case studies. One uses SAP R/3 system and another uses IFS system. The research consisted of conducting a series of one-to-one interview with experienced participants. The results of interview are summary with the others related reports and literature. The aim of this paper is to unveil what successful factors may contribute to system implementation special to construction industry.

\section{CRITICAL FACTORS FOR SUCCESSFUL ERP IMPLEMENTMENT}

Implementing an ERP system is not an inexpensive or risk-free venture. In fact, $65 \%$ of executives believe that ERP systems have at least a moderate chance of hurting their businesses because of the potential for implementation problems. It is therefore worthwhile to examine the factors that, to a great extent, determine whether the implementation will be successful. Numerous authors have identified a variety of factors that can be considered to be critical to the success of an ERP implementation. The most prominent of these are described below (see Figure 1).

\subsection{Clear understanding of strategic goals}

ERP implementations require that key people throughout the organization create a clear, compelling vision of how the company should operate in order to satisfy customers, empower employees, and facilitate suppliers for the next three to five years. There must also be clear definitions of goals, expectations, and deliverables. Finally, the organization must carefully define why the ERP system is being implemented and what critical business needs the system will address.

\subsection{Organizational change management}

Implementing an ERP system involves reengineering the existing business processes to the best business process standard. One of the principal reasons why ERP and other large technologically sophisticated systems fail is that organizations simply underestimate the extent to which they have to change and re-engineering the existing business processes in order to accommodate their purchase. ERP systems are built on best practices that are followed in the industry. All the processes in a company must conform to the ERP model. Dimensions concerning business process reengineering are: (1) Company's willingness to reengineering; (2) Company's readiness for change; (3) Company's capability of reengineering; and (4) Communication. Prior studies claimed that the more willing an organization is to change, the more successful the implementation. There should exist the trust between top management and the staff within the company, which would facilitate the change process. While communication is another determinant factor affecting successful BPR implementation in that BPR is a radical redesign of the company's current culture, structure, and process. If people within the company were not given enough information about the purposes of BPR, they would feel uncertainty about their jobs, which can impede the progress of reengineering. Management should answer every employee question and held company-wide meetings to make the strategy understood by every people.

\subsection{Top management Support}

Many study have stressed the importance of top management support as a necessary ingredient in successful ERP implementation because successful implementations require strong leadership, commitment, and participation by top management. Since executive level input is critical when analyzing and rethinking existing business processes, the implementation project should have an executive management planning committee that is committed to enterprise integration, understands ERP, fully supports the costs, demands payback, and champions the project. Moreover, the project 
should be spearheaded by a highly-respected, executive-level project champion.

\subsection{Excellent project management}

ERP systems implementation is a set of complex activities, involving all business functions and often requiring between one and two years of effort, thus companies should have an effective project management strategy to control the implementation process, avoiding overrun of budget and ensuring the implementation within schedule. There are six major parts of project management: (1) having a clear implementation strategic, (2) having a formal implementation plan, (3) a realistic time frame, (4) having periodic project status meetings, (5) having an effective project leader who is also a champion, and (6) having project team members who are stakeholders. The formal project implementation plan defines project activities, commits personnel to those activities, and promotes organizational support by organizing the implementation process. Having a realistic time frame is very important. If the target completion time schedule were unrealistically short, the pressure to rush through would result in the implementation being carried out in a haphazard manner. On the other hand, if the implementation delayed for too long, people would tend to lose faith and/or patience, which also will result in low morale and resistance. Conducting periodic project status meetings in which each team member reports progress and problems is an invaluable means for evaluating the progress of the ERP implementation. Selecting the right project leader is also important for the project implementation success.

\subsection{Data accuracy}

Data accuracy is absolutely required for an ERP system to function properly. Because of the integrated nature of ERP, if someone enters the wrong data, the mistake can have a negative domino effect throughout the entire enterprise information system. Therefore, educating users on the importance of data accuracy and correct data entry procedures should be a top priority in an ERP implementation. ERP systems also require that everyone in the organization must work within the system, not around it. Employees must be convinced that the company is committed to using the new system, will totally changeover to the new system, and will not allow continued use of the old system. To reinforce this commitment, all old and informal systems must be eliminated. If the organization continues to run parallel systems, some employees will continue using the old systems.

\subsection{Full-time implementation team}

Full-time implementation team should be selected to lead the implementation action. ERP implementation teams should be composed of topnotch people who are chosen for their skills, past accomplishments, reputation, and flexibility. These people should be entrusted with critical decision making responsibility. Management should constantly communicate with the team, but should also enable empowered, rapid decision making. The implementation team is important because it is responsible for creating the initial, detailed project plan or overall schedule for the entire project, assigning responsibilities for various activities and determining due dates. The team also makes sure that all necessary resources will be available as needed.

\subsection{Extensive education and training}

Education and training are probably the most widely recognized critical success factor, because user understanding and buy-in is essential. ERP implementation requires a critical mass of knowledge to enable people to solve problems within the framework of the system. If the employees do not understand how a system works, they will invent their own processes using those parts of the system they are able to manipulate. The full advantages of ERP cannot be realized until end users are using the new system properly. To make end user training successful, the training should start early, preferably well before the implementation begins. Executives often dramatically underestimate the level of education and training necessary to implement an ERP system as well as the associated costs. Top management must be fully committed to spend adequate money on education and end user training and incorporate it as part of the ERP budget. It has been suggested that reserving $15-20 \%$ of the total ERP implementation budget for training will give an organization an $90 \%$ chance of implementation success. All too often, employees are expected to be able to effectively use the new system based only on education and training. Yet, much of the learning process comes from hands-on use under normal operating conditions. Thus, a designated individual (preferably the project leader) should maintain ongoing contact with all system users and monitor 
the use of, and problems with, the new system. There is also a need for post-implementation training. Periodic meetings of system users can help identify problems with the system and encourage the exchange of information gained through experience and increasing familiarity with the system.

\subsection{Multi-sites Consideration}

Multi-site implementations present special concerns. The manner in which these concerns are addressed may play a large role in the ultimate success of the ERP implementation. The desired degree of individual site autonomy may be a critical issue which depends on two factors: (1)the degree of process and product consistency across the remote sites, and (2)the need or desire for centralized control over information, system setup, and usage. One of the objectives of an ERP implementation may be to increase the degree of central control through the implementation of standardized processes. Alternatively, the implementation may be undertaken in order to provide the remote sites with capabilities that allow them to fine tune their processes to their unique situations. Another complexity in dealing with multi-site implementations is the degree to which the culture of the organization differs between sites. The fundamental issue here is one of corporate standardization versus local optimization. Corporate standardization brings with it simplified interfaces among diverse parts of the organization, ability to move people and products between sites with minimal disruption, and relative ease in consolidating data across the entire organization. On the other hand, local optimization may result in more effective and efficient operation and may reduce costs. Perhaps the most difficult decision to be made in a multi-site implementation is the question of cutover strategy. The organization must choose between an approach where the implementation takes place simultaneously in all facilities or a phased approach by module, by product line, or by plant with a pilot implementation at one facility. With a large outlay of cash up front for software, hardware, and the project team, the company may want a simultaneous implementation in order to recoup its investment as quickly as possible. In a multi-site implementation, a phased approach is generally considered to be preferable. This is partly because the success or failure experienced in the first attempt at implementation often decides the fate of the entire project. Thus, the management team can gain momentum by selecting a pilot site that has a high likelihood of success. And if ERP is installed in a phased approach module by module, department by department, or plant by plant - the lessons learned at early sites can make the implementations at later sites go smoother.

\subsection{Effective performance measures}

Effective performance measures that assess the impact of the new system must be carefully constructed. Of course, the measures should indicate how the system is performing. But the measures must also be designed so as to encourage the desired behaviors by all functions and individuals. Such measures might include on-time deliveries, gross profit margin, customer order-toship time, inventory turns, vendor performance, etc. Project evaluation measures must be included from the beginning. If system implementation is not tied to compensation, it will not be successful. For example, if all managers will get their raises and bonuses next year even if the system is not implemented, successful implementation is less likely. Management, vendors, the implementation team, and the users must share a clear understanding of the goal. If someone is unable to achieve agreed-upon objectives, they should either receive the needed assistance or be replaced. When teams reach their assigned goals, rewards should be presented in a very visible way. The project must be closely monitored until the implementation is completed. The system must be forever monitored and measured. Management and other employees often assume that performance will begin to improve as soon as the ERP system becomes operational. Instead, because the new system is complex and difficult to master, organizations must be prepared for the possibility of an initial decline in productivity. As familiarity with the new system increases, improvements will occur. Thus, realistic expectations about performance and time frames must be clearly communicated.

\subsection{Consultant Vendor Support}

Consultant vendor play a important role in the ERP implementation. Most local companies purchase ERP packages from foreign ERP vendors and ERP represent the best-practice processes that is different from Taiwan's organizational business process, thus, it's necessary and important to get the consultant vendor support. Three dimensions of consultant vendor support are classified: (1) Service response time of the software vendor; (2) Qualified 
consultants with professional knowledge in both enterprises' business processes and information technology including consultant vendors' ERP systems; and (3) Participation of vendor in ERP implementation. It's important for the consultant vendor's staffs to be knowledgeable in both business processes and ERP system functions. Also, the consultants should possess good interpersonal skills and be able to work with people. Software vendors should be carefully selected since they play a crucial part in shaping the ultimate outcome of the implementation.

\section{CONCLUSION}

This paper aims to improve understanding of critical factors affecting ERP implementation success in construction industries. The interview of four construction companies in Taiwan implementing the ERP system is made to summary and discuss in terms of these key factors for successful ERP implementation. However, due to the small sample size in the survey, there are some limitations in the generalization of the research results to a larger population. Meanwhile, ERP implementation is not a short-term project lasting only two or three months, but a long-term program which may last for one or several years. Factors affecting ERP implementation are complex and abundant, thus many researchers conduct case study only to find out some specific problems with ERP implementation. Undoubtedly, detailed case study is a powerful tool to solicit important issues disregarding to its disadvantage of generalization problems. Thus, combining detailed case study and a large survey would be an helpful method to improve the successful ERP implementation special for the construction industries.

\section{REFERENCES}

Avraham Shtub (2001), "A framework for teaching and training in the ERP era," International Journal of Production Research, Vol.39, No.3, 567-576

Anand Teltumbde (2000), "A framework for evaluating ERP projects," Journal of Information Technology, Vol.38, No.17, 4507-4520

A. Angerosa (1999), The future looks bright for ERP, APICS - The Performance Advantage (October) 5-6.
Avraham Shtub (1999), Enterprise Resource Planning (ERP):The Dynamics of Operations Management, Kluwer Academic Publishers.

C. Dillon (1999), Stretching toward enterprise flexibility with ERP, APICS-The Performance Advantage.

C. Ptak, E. Schragenheim (2000), ERP: Tools, Techniques, and Applications for Integrating the Supply Chain, St. Lucie Press, Boca Raton, FL.

G. Buchanan, P. Daunais (2000), C. Micelli, Enterprise resource planning: A closer look, Purchasing Today.

G. Langenwalter (2000), Enterprise Resources Planning and Beyond: Integrating Your Entire Organization, St. Lucie Press, Boca Raton, FL,.

J. Krupp (1998), Transition to ERP implementation, APICS - The Performance Advantage.

James T. O'Connor, Steven C. Dodd (2000), "Achieving integration on capital projects with enterprise resource planning systems," Automation in Construction 9, 515-524.Karl M.

J.K.C. NG, W. H. IP, and T.C. LEE (1999), "A paradigm for ERP and BPR integration," Journal of Information Technology, Vol.37, No.9, 2093-2108

Kapp, William F. Latham, and Hester N.FordLatham (2000), ERP Success-A learning Requirements Planning Approach, The St. Lucie Press.

M. Lynne Markus, et al (2000), "Learning from adopters' experiences with ERP: problems encountered and success achieved," Journal of Information Technology 15, 245-265.

M.H. Martin (1998 February), "An ERP Strategy”, Fortune, pp 95-97 


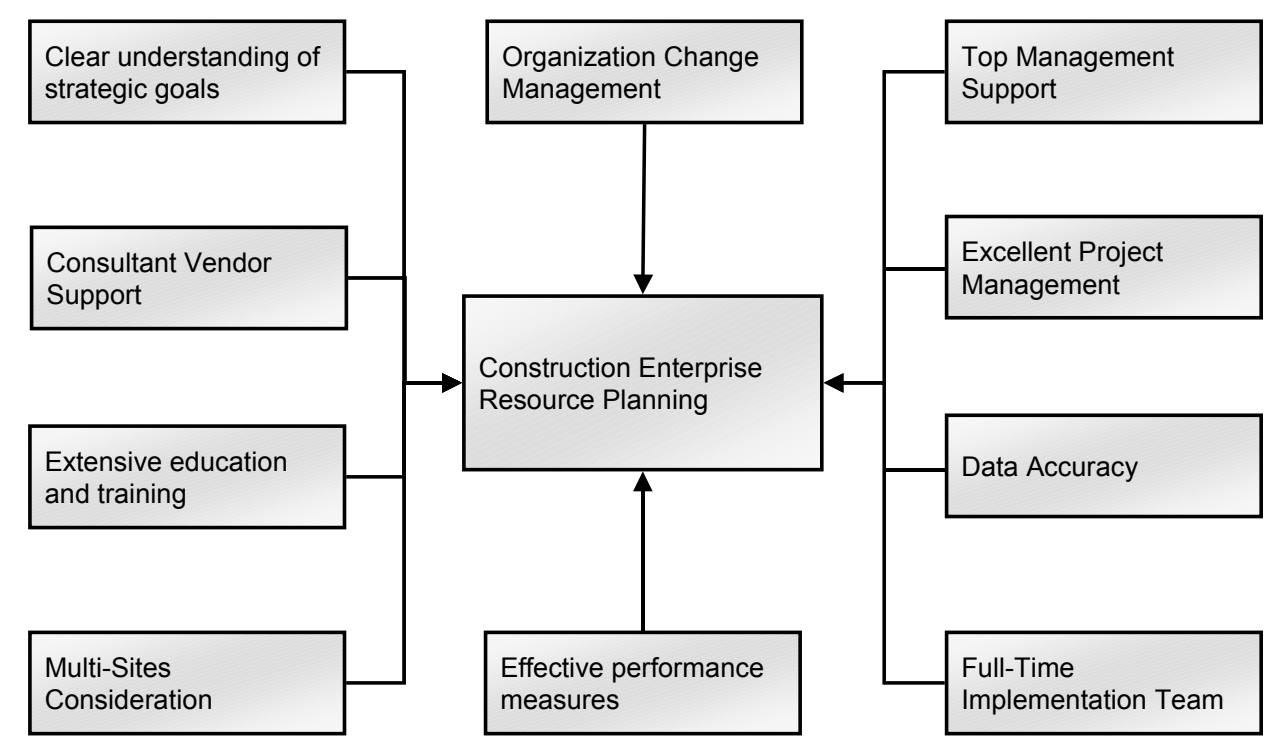

Figure 1. Critical Success Factors of ERP System for Construction industry. 